\title{
Carve-Outs Under Airline Antitrust Immunity
}

\author{
by \\ Jan K. Brueckner \\ Department of Economics \\ University of California, Irvine \\ 3151 Social Science Plaza \\ Irvine, CA 92697 \\ e-mail: jkbrueck@uci.edu \\ and \\ Stef Proost \\ Center for Economic Studies \\ KULeuven \\ Naamsestraat 69 \\ 3000 Leuven, Belgium \\ e-mail: stef.proost@econ.kuleuven.be
}

October 2009

\begin{abstract}
This paper offers the first formal economic analysis of carve-outs under airline antitrust immunity. Carve-outs are designed to limit the potential anticompetitive effects of cooperation by alliance partners in hub-to-hub markets, where they provide overlapping nonstop service. While the paper shows that carve-outs are beneficial when the alliance does not involve full integration of the partners' operations on the hub-to-hub route, its key point is that a carveout may be harmful when imposed on a joint-venture alliance. A JV alliance involves full exploitation of economies of traffic density on the hub-to-hub route, and a carve-out prevents the realization of these benefits. While a carve-out may limit anticompetitive incentives on the hub-to-hub route, welfare may be reduced if the resulting gains are overshadowed by the efficiency loss generated by the carve-out.
\end{abstract}




\title{
Carve-Outs Under Airline Antitrust Immunity
}

\author{
by
}

\author{
Jan K. Brueckner and Stef Proost*
}

\section{Introduction}

Prohibitions on cross-border airline mergers preclude full integration of US and foreign carriers. But international alliances facilitate substantial cooperation between airlines, especially when the alliance partners enjoy antitrust immunity (ATI). Immunity for an alliance allows collaboration in the provision of international service in two principal types of markets. One market type involves travel between smaller US and foreign cities, which requires an "interline" trip that crosses the networks of the two alliance partners. The other market type involves nonstop travel between the partners' (larger) hub cities, where overlapping service allows the trip to be made using either the US airline or its partner. Immunity has often been granted in conjunction with an open-skies agreement between the US and the home country of a partner airline.

The effects of alliances and ATI on airfares have been extensively investigated in the economics literature. Theory predicts that, for interline trips, cooperation in fare setting under ATI eliminates a type of horizontal double marginalization. Instead of non-cooperatively setting the components of an interline fare for travel across two networks, the two carriers under ATI jointly set the entire fare, reducing their two separate "markups" to one. The result is a lower interline fare, which benefits passengers. By contrast, in allowing cooperation on overlapping nonstop hub-to-hub routes, ATI introduces a potential anticompetitive effect. Cooperating carriers may have an incentive to raise fares for origin-destination passengers on these routes, restricting the number of hub-to-hub tickets sold and boosting the carriers' combined profits. This effect may emerge even while interline traffic using the hub-to-hub route rises.

Brueckner (2001) provides a theoretical analysis of both effects, showing that, while the net 
welfare impact on consumers is generally ambiguous, the beneficial impact in interline markets is likely to offset the potential negative effect in nonstop markets, making the overall effect of ATI positive. This outcome is especially likely when the hub-to-hub market is small relative to the full set of interline markets, involving relatively few origin-destination passengers.

Brueckner and Whalen (2000), Brueckner (2003), Whalen (2007), and Willig, Israel and Keating (2009) provide empirical evidence on the size of the interline fare discount from cooperative pricing, which may be as large as 25\%. Brueckner and Whalen (2000) and Willig et al. (2009) also show that the fare impact of alliance cooperation on hub-to-hub routes is effectively zero, contrary to expectations. A growing set of additional papers further explores economic issues related to airline alliances. ${ }^{1}$ Similar tradeoffs involving horizontal (as well as vertical) integration, economies of scale, and anticompetitive behavior emerge in other transportation contexts (freight, high-speed rail), as shown by De Borger, Dunkerley and Proost (2007) and De Borger, Proost and Van Dender (2008).

Despite the absence of a measured fare impact on hub-to-hub routes, concerns about potential anticompetitive effects persist. In response, regulators have occasionally imposed "carveouts" in such markets when granting ATI. A carve-out prohibits collaboration in hub-to-hub fare setting, while allowing cooperation in other markets. For example, in granting immunity to United and Lufthansa (founding partners of the Star alliance), the US Department of Transportation imposed carve-outs in the Chicago-Frankfurt and Washington (Dulles)-Frankfurt markets, which connect United and Lufthansa hubs, while allowing the carriers to set fares cooperatively elsewhere. By contrast, in its early grant of ATI to Northwest and KLM, carveouts were not imposed in their hub-to-hub markets (Detroit-Amsterdam and MinneapolisAmsterdam), mainly based on the small size of these markets. Similarly, carve-outs were not imposed in any of the markets connecting the hubs of Delta and Air France, founding members of the SkyTeam alliance (Atlanta-Paris, among others).

Recently, however, carve-outs have emerged as a contentious regulatory issue. In its tentative approval of Star-alliance ATI for Continental (a former SkyTeam member), the DOT required no new hub-to-hub carve-outs. However, in an advisory opinion, the US Department of Justice strongly recommended a number of such carve-outs as well as other limitations to 
the scope of ATI, and in its final order, the DOT acquiesced in many of the DOJ carve-out recommendations (see USDOJ (2009) and USDOT (2009)). These carve-outs involved routes between the New York area and several secondary Star hubs (Stockholm, Zurich, Copenhagen), and routes between Continental's hubs and Air Canada's Toronto hub along with several additional Canadian endpoints.

Despite the centrality of carve-outs in this latest ATI decision, the economics literature on alliances offers no treatment whatsoever of this topic. Since the carve-out issue is likely to arise in future ATI cases, especially the pending ATI application of American Airlines and British Airways (AA and BA), this omission requires a remedy. Accordingly, the present paper develops a theoretical treatment of the carve-out issue using a highly-stylized model based on the one analyzed by Brueckner (2001).

The model adds a key feature to this earlier analytical framework, which captures an important new development in the structure of alliances that is germane to the carve-out issue: the emergence of the "joint venture" as a common alliance form. Under a joint venture (JV) alliance, the carriers engage in comprehensive revenue sharing on international routes, so that a partners' revenue from a passenger is independent of which airline actually provides the service. This arrangement leads to what is known as a "metal neutral" alliance structure, in the sense that the identity of the "metal" (the aircraft) involved in the service is irrelevant to individual airline revenue. Although Northwest and KLM operated a JV alliance starting in the early 1990s, this form has only recently spread to the other alliances. SkyTeam operates a JV, and as does the Star alliance (with Continental now participating), and the pending ATI application of AA and BA also envisions a joint venture.

The paper adopts a particular analytical representation of a joint venture, which affects the model's portrayal of hub-to-hub routes. In the absence of a JV, the alliance partners are assumed to operate separate services on the hub-to-hub route, not capturing the full benefits of integration. With a JV, however, the hub-to-hub services are consolidated, as under a true merger. This difference affects the exploitation of economies of traffic density (increasing returns to scale) on the hub-to-hub route. Economies of density are a hallmark of airline network models, and their existence implies that cost per passenger falls as the traffic volume 
on a route rises, a result of the use of larger, more efficient aircraft and the spreading of fixed endpoint costs over more passengers. While a non-JV alliance divides hub-to-hub traffic between two separate airline operations, a JV alliance consolidates this traffic under a single unified entity, achieving (under the model) greater efficiencies from higher traffic density. Given the stylized nature of the framework, other efficiencies from the JV alliance, including moreeffective scheduling, cannot be captured. For a good discussion of the nature of such additional benefits, see the response of American Airlines to the criticisms in USDOJ (2009) (American Airlines (2009)). Such benefits might be capturable in a more-complete model, but at the cost of much greater complexity.

With this representation of a JV alliance, the trade-off involved in carve-outs becomes clear. By preventing collaboration in the hub-to-hub market, a carve-out eliminates a key element of a JV alliance, consolidation of operations on this route. This loss reduces the efficiency of the alliance, raising cost per passenger on the hub-to-hub route. Offsetting this downside, however, are potential competitive gains. In particular, eliminating collaboration in the hub-to-hub market prevents a possible anticompetitive increase in the hub-to-hub fare under the alliance. Whether the carve-out is harmful or beneficial depends on the net effect of these two forces. If the efficiency loss is substantial relative to any competitive gains, then the carve-out can be harmful, while a small efficiency loss will yield the opposite verdict.

It should be noted that, under the model, the resolution of the carve-out issue involves considerations that go beyond the market that is directly affected. The reason is that interline passengers also travel on the hub-to-hub route, and they are affected by the rules governing this route. Harm from an undesirable hub-to-hub carve-out can extend to these passengers, while they may also benefit from a desirable carve out.

Another important insight of the analysis is that imposition of a carve-out on a non-JV alliance has no efficiency downside and is thus desirable in the context of the model. In other words, since non-JV alliance partners do not operate consolidated service on the hub-to-hub route, banning collaboration on this route generates no efficiency loss. However, competitive benefits emerge, so that the carve-out is in the public interest, leading to a better outcome than a non-JV alliance without a carve-out. 
It is interesting to note that the DOT's final order in the Continental-Star ATI case is consistent with this logic. Carve-outs were imposed only on routes that are not part of the enlarged joint venture. Carve-outs on JV routes were not required, and existing carve-outs on the routes connecting Chicago and Washington to Frankfurt (which are part of the JV) were removed.

The plan of the paper is as follows. Section 2 sets up the model. Section 3 analyzes the airlines' profit maximization problem and develops the equilibrium conditions for four cases: a JV alliance, a non-JV alliance, an alliance carve-out (where the JV/non-JV distinction ceases to matter), and the no-alliance case. Section 4 compares the outcomes in the four cases. A few results analogous to those of Brueckner (2001) are derived for the current model, and the key conclusions regarding carve-outs, as sketched above, are then proved. Section 5 presents a numerical example based on specific functional forms in order to resolve some of the ambiguities of the theory, and section 6 presents conclusions.

\section{The Model}

\subsection{Network}

In order to produce a tractable analysis, the model assumes simpler network and market structures than in Brueckner (2001). This structure is illustrated in Figure 1. Carrier 1, the US carrier, operates a route between city A (an interior US endpoint) and city H (its hub and international gateway). In addition, it operates a route between $\mathrm{H}$ and city $\mathrm{J}$ in Europe. This latter city serves as the hub and gateway for carrier 2, the EU carrier. That carrier operates a route between the two hubs, $\mathrm{H}$ and $\mathrm{J}$, while also operating a route between $\mathrm{J}$ and the interior European endpoint B. Carrier 1's routes are shown as solid lines, while carrier 2's routes are shown as dotted lines. Note that carriers 1 and 2 provide overlapping nonstop service between H and J. Brueckner's (2001) network structure differs by including two interior endpoints in each region, each connected to the relevant hub. While this structure would highlight the hub roles of $\mathrm{H}$ and $\mathrm{J}$, it adds nothing essential to the analysis. ${ }^{2}$

\subsection{Travel demands}

For simplicity, demand for travel is assumed to exist in only two of the potential city-pair 
markets in Figure 1: markets $\mathrm{AB}$ and HJ. Thus, passengers living in city $\mathrm{H}$ travel to city J and back, and passengers living in city J similarly make round trips to city $\mathrm{H}$ and back. Such trips involve nonstop flights, and without loss of generality, passengers are assumed to use their home airline, so that $\mathrm{H}$ residents use airline 1 and $\mathrm{J}$ residents use airline 2. Symmetry is assumed, so that the number of round-trip passengers originating at $\mathrm{H}$ equals the number originating at J. This number is given by the demand function $d\left(p_{h j}\right) / 2$, where $p_{h j}$ is the common round-trip fare charged in market HJ by the two airlines. ${ }^{3}$ Total travel demand in the HJ market (round-trip passengers originating either at $\mathrm{H}$ or $\mathrm{J}$ ) is then double this value, or $d\left(p_{h j}\right)$. The inverse demand function is given by $D\left(q_{h j}\right)$, where $q_{h j}$ is total round-trip travel in the market (the sum of originations at $\mathrm{H}$ and $\mathrm{J}$ ).

The second market where travel demand exists is AB. Passengers living in the interior US city A make round trips to the interior EU city B, while passengers living in city B make round trips to city A. Since a direct route between A and B does not exist, such a trip involves a double connection as well as interline travel. Passengers originating in city A fly to hub $\mathrm{H}$ on airline 1, where they change planes and fly onward to the EU hub J, again on airline 1. At $\mathrm{J}$, the passengers transfer to airline 2 for the final leg to city B, retracing their steps on the journey home. Similarly, AB passengers originating at B fly to J, where they change planes for the onward trip to $\mathrm{H}$ (staying on airline 2). They transfer to airline 1 at $\mathrm{H}$ for the final leg to city A, and then retrace their steps to return. Note that, without loss of generality, passengers in market $\mathrm{AB}$ are assumed to stay on their home airline as long as possible. In other words, A-originating passengers use airline 1 to reach $\mathrm{J}$, when they could actually use airline 2 for the trip between $\mathrm{H}$ and $\mathrm{J}$ (similarly for B-originating passengers).

Letting $p_{a b}$ denote the fare in market $\mathrm{AB}$, which will be symmetric regardless of origin, the total travel demand in the market is given by $d\left(p_{a b}\right)$ (which is the sum of passengers originating at $\mathrm{A}$ and $\mathrm{B})$. The inverse demand is $D\left(q_{a b}\right)$, where $q_{a b}$ is total AB traffic. Note that, to ease the notational burden and without loss of generality, the demand functions are assumed to be the same in the AB and HJ markets.

Figure 1 includes four additional potential city-pair markets, and travel demand in these markets is assumed to be zero. The first market is AH, which involves travel between the 
interior US endpoint and airline 1's hub. The second market is AJ, involving travel between A and the EU hub city J. For simplicity, travel is suppressed in these markets, and demand in the parallel markets BJ and BH is also assumed to be absent. Brueckner's (2001) analysis includes these types of markets, but at the cost of additional algebraic complexity. Since the economic issues involving alliances and carve-outs arise only in markets $\mathrm{HJ}$ and $\mathrm{AB}$, suppression of these additional markets is warranted.

\subsection{Costs}

Airline costs, which are symmetric across carriers 1 and 2, consist of the cost of operating individual route segments, with other potential systemwide costs (fixed or otherwise) suppressed. The route cost functions exhibit economies of traffic density, or increasing returns to scale (constant returns is considered as a polar case). The economies of operating larger aircraft, which have a lower cost per seat than smaller aircraft, are well recognized in the literature, and economies of density can also reflect the fixed costs of check-in and baggage-handling facilities at the endpoints of a route. Accordingly, the cost of carrying $T$ round-trip passengers on route HJ is given by $C(T)$, where $C^{\prime}>0$ and $C^{\prime \prime} \leq 0$. Routes $\mathrm{AH}$ and BJ are assumed to have the same length as route HJ, thus sharing the same cost function. Therefore, the cost of carrying $T$ round-trip passengers on either of these routes is given by $C(T)$. As in the case of demands, this common-cost assumption is meant to simplify notation and has little effect on the results.

A carrier's total traffic $T$ on a route segment depends on city-pair traffic. Consider first the "interior" routes AH and BJ. Since each round-trip passenger in the AB market travels on both the $\mathrm{AH}$ and the BJ routes, regardless of whether he/she originates at A or B, airline 1's traffic on route AH equals $q_{a b}$ and airline 2's traffic on route BJ also equals $q_{a b}$. Thus, letting $T_{i}$ denote traffic on the interior routes $\mathrm{AH}$ and BJ, $T_{i}=q_{a b}$ holds, so that each airline incurs a cost of $C\left(q_{a b}\right)$ in operating its interior route.

Total traffic on the interhub route HJ, by contrast, consists of passengers traveling in market $\mathrm{AB}$ and passengers traveling in the HJ market itself. Thus, total traffic on the HJ route is $T_{h j} \equiv q_{a b}+q_{h j}$. How this passenger volume translates into carrier costs depends on the degree of integration of the two airlines. In the no-alliance case, carriers 1 and 2 compete 
on the HJ route and thus operate separate flights. Given symmetry, the carriers divide the total traffic equally, each carrying $T_{h j} / 2$ passengers and incurring a cost of $C\left(T_{h j} / 2\right)$ on the HJ route.

By contrast, under a joint-venture (JV) alliance, the two airlines will effectively merge their international services, so that duplicate costs will no longer be incurred. As a result, the overall cost of operating the HJ route is now given by $C\left(T_{h j}\right)$, with each airline's share of this total equalling $C\left(T_{h j}\right) / 2$. Total traffic volume in the HJ route will in general differ between the no-alliance and JV alliance cases, so that the $T_{h j}$ values in this and the previous cost expression will not be the same. However, holding $T_{h j}$ fixed, the existence of economies of density means that $C\left(T_{h j} / 2\right)>C\left(T_{h j}\right) / 2$, so that the JV alliance leads to cost savings when traffic is held constant. The reason is that combined rather than separate operations allow fuller exploitation of economies of density.

In the non-JV alliance case, by contrast, separate operations are maintained on the HJ route, just as in the no-alliance case. As a result, each carrier incurs a cost of $C\left(T_{h j} / 2\right)$ for a given volume of traffic on the HJ route (again, this volume will generally differ from the above cases).

Depending on the degree of integration, a carve-out can affect an alliance's cost structure. In the non-JV alliance case, a carve-out has no cost effect, serving only to preclude collaboration in the HJ market. However, a carve-out does change the structure of costs for a JV alliance. By preventing a merger on the HJ route, traffic must be divided across separate flight operations, so that each airline's cost is $C\left(T_{h j} / 2\right)$ rather than $C\left(T_{h j}\right) / 2$. Thus, under a carve out, JV and non-JV alliances are rendered equivalent, with separate costs incurred on the HJ route and collaboration precluded in the HJ market.

\section{Profit Maximization and Equilibrium Conditions}

\subsection{Alliances without carve outs}

First consider profit maximization under alliances in the absence of carve-outs. In these cases, the airlines collaborate in setting fares in both the $\mathrm{AB}$ and $\mathrm{HJ}$ markets. In the $\mathrm{AB}$ market, the alliance partners determine a fare $p_{a b}$ for the entire trip between the $\mathrm{A}$ and $\mathrm{B}$ 
endpoints, and they split the revenue from the market under a symmetric prorate agreement. In the HJ market, the airlines determine a common fare that maximizes their individual and thus combined profits.

Consider first the non-JV alliance. For clarity, it is useful to write individual airline profit in two equivalent forms, with the first using fares. Individual airline profit is equal to

$$
\pi^{n o n-j v}=\frac{1}{2} p_{a b} d\left(p_{a b}\right)+\frac{1}{2} p_{h j} d\left(p_{h j}\right)-C\left[d\left(p_{a b}\right)\right]-C\left[\left(d\left(p_{a b}\right)+d\left(p_{h j}\right)\right) / 2\right] .
$$

Note that each airline earns revenue from two markets (AB and HJ) while incurring costs from operating two routes, its interior route and the HJ route.

Profit can also be written in terms of quantities rather than fares. The relevant expression is

$$
\pi^{n o n-j v}=\frac{1}{2} q_{a b} D\left(q_{a b}\right)+\frac{1}{2} q_{h j} D\left(q_{h j}\right)-C\left(q_{a b}\right)-C\left[\left(q_{a b}+q_{h j}\right) / 2\right] .
$$

In this case, the alliance members are portrayed as jointly choosing quantities to maximize individual profits, with fares given via the inverse demand functions.

Using (2), the first-order conditions for choice of $q_{a b}$ and $q_{h j}$ are

$$
\begin{aligned}
& \pi_{a b}^{n o n-j v}=D\left(q_{a b}\right)+q_{a b} D^{\prime}\left(q_{a b}\right)-2 C^{\prime}\left(q_{a b}\right)-C^{\prime}\left[\left(q_{a b}+q_{h j}\right) / 2\right]=0 \\
& \pi_{h j}^{n o n-j v}=D\left(q_{h j}\right)+q_{h j} D^{\prime}\left(q_{h j}\right)-C^{\prime}\left[\left(q_{a b}+q_{h j}\right) / 2\right]=0,
\end{aligned}
$$

where the subscripts on $\pi$ denote derivatives with respect to $q_{a b}$ and $q_{h j}$. The first two terms in (3) give marginal revenue from a passenger in the $\mathrm{AB}$ market while the last two terms give marginal cost of serving a passenger, which equals marginal cost on two interior routes plus marginal cost on the interhub HJ route. Similarly, the first two terms in (4) give marginal revenue in the HJ market, while the last term is marginal cost on the single route used in serving the market.

By contrast, the HJ cost expression differs under a JV alliance in the manner explained above, so that the quantity-based profit expression analogous to (2) in the JV case becomes

$$
\pi^{j v}=\frac{1}{2} q_{a b} D\left(q_{a b}\right)+\frac{1}{2} q_{h j} D\left(q_{h j}\right)-C\left(q_{a b}\right)-\frac{1}{2} C\left(q_{a b}+q_{h j}\right) .
$$


The first-order conditions analogous to (3) and (4) are

$$
\begin{aligned}
& \pi_{a b}^{j v}=D\left(q_{a b}\right)+q_{a b} D^{\prime}\left(q_{a b}\right)-2 C^{\prime}\left(q_{a b}\right)-C^{\prime}\left(q_{a b}+q_{h j}\right)=0 \\
& \pi_{h j}^{j v}=D\left(q_{h j}\right)+q_{h j} D^{\prime}\left(q_{h j}\right)-C^{\prime}\left(q_{a b}+q_{h j}\right)=0 .
\end{aligned}
$$

Note that, because of combined operations on HJ route under the joint venture, marginal cost is given by $C^{\prime}$ evaluated at the total traffic level $q_{a b}+q_{h j}$, rather than half that level.

The second-order conditions for the two profit maximization conditions are assumed to hold. Intuitively, given that both marginal revenue $(M R)$ and marginal cost $(M C)$ are decreasing in quantities, these conditions in part require that $M R$ is decreasing faster than MC.

\subsection{Alliances with a carve out}

Under a carve-out, the alliance partners must compete in the HJ market while being allowed to cooperate in the $\mathrm{AB}$ market. As explained above, this competition requirement precludes joint operations on the HJ route, so that individual airline cost on this route is $C\left[\left(q_{a b}+q_{h j}\right) / 2\right]$. Thus, the effect of the joint venture is eliminated, with the profit expressions being identical in the two cases.

Since the carriers must compete in the HJ market, they choose individual traffic levels in this market rather than collaborating in setting a common traffic level. Let the traffic levels

for carriers 1 and 2 be denoted $q_{h j}^{1}$ and $q_{h j}^{2}$, variables that are distinct for purposes of profit maximization but that will end up being equal in the symmetric equilibrium. Airline 1's profit is then given by

$$
\pi^{\text {carve }}=\frac{1}{2} q_{a b} D\left(q_{a b}\right)+q_{h j}^{1} D\left(q_{h j}^{1}+q_{h j}^{2}\right)-C\left(q_{a b}\right)-C\left(q_{a b} / 2+q_{h j}^{1}\right)
$$

with a parallel expression applying for airline 2 . Note that $q_{h j}^{1}$ rather than $q_{h j} / 2$ multiplies the HJ inverse demand (which now depends on the sum of the individual traffic levels), and that the same modification appears inside the HJ cost expression.

With Cournot behavior, the first-order conditions under a carve-out are found by differentiating (8) with respect to $q_{a b}$ and $q_{h j}^{1}$, holding $q_{h j}^{2}$ fixed. The symmetric equilibrium is then 
determined by setting $q_{h j}^{1}=q_{h j}^{2}=q_{h j} / 2$ in these expressions. The resulting conditions are

$$
\begin{aligned}
& \pi_{a b}^{\text {carve }}=D\left(q_{a b}\right)+q_{a b} D^{\prime}\left(q_{a b}\right)-2 C^{\prime}\left(q_{a b}\right)-C^{\prime}\left[\left(q_{a b}+q_{h j}\right) / 2\right]=0 \\
& \pi_{h j}^{\text {carve }}=D\left(q_{h j}\right)+\frac{1}{2} q_{h j} D^{\prime}\left(q_{h j}\right)-C^{\prime}\left[\left(q_{a b}+q_{h j}\right) / 2\right]=0 .
\end{aligned}
$$

Note that these conditions are the same as (6)-(7) except that $1 / 2$ appears before the second expression, reflecting the fact that $M R$ in the HJ market differs when the carriers compete instead of collaborating.

\subsection{No alliance}

In the no-alliance case, the airlines compete in market HJ and also behave in non-cooperative fashion in market AB. Following Brueckner (2001), this latter behavior involves the non-cooperative choice of "subfares," which represent the individual carrier revenue earned from interline $\mathrm{AB}$ trips.

Each airline determines its AB subfare to maximize profit, taking the other airline's subfare as given and recognizing that the overall $\mathrm{AB}$ fare equals the sum of the subfares. This subfare choice involves double marginalization, in that each carrier individually affects the $\mathrm{AB}$ fare via its subfare choice. Let $s_{a b}^{1}$ denote airline 1's subfare and $s_{a b}^{2}$ denote 2's subfare, with $p_{a b}=s_{a b}^{1}+s_{a b}^{2}$. Note that while airline 1 carries A-originating AB passengers farther than B-originating $\mathrm{AB}$ passengers (on both the $\mathrm{AH}$ and $\mathrm{HJ}$ routes rather than just the $\mathrm{AH}$ route),

the subfare $s_{a b}^{1}$ can be viewed as the average amount earned from these two types of passengers, with a similar observation applying to $s_{a b}^{2}$ and airline $2 .^{4}$

Given the choice of subfares in market AB, the airline profit expression in the no-alliance case cannot be written entirely in terms of quantities, as in the previous cases. Profit for airline 1 is given by

$$
\pi^{\text {none }}=s_{a b}^{1} d\left(s_{a b}^{1}+s_{a b}^{2}\right)+q_{h j}^{1} D\left(q_{h j}^{1}+q_{h j}^{2}\right)-C\left[d\left(s_{a b}^{1}+s_{a b}^{2}\right)\right]-C\left[d\left(s_{a b}^{1}+s_{a b}^{2}\right) / 2+q_{h j}^{1}\right] .
$$

The first term is revenue from the $\mathrm{AB}$ market, equal to the subfare $s_{a b}^{1}$ times $\mathrm{AB}$ traffic, which is given by the direct demand function $d(\cdot)$ evaluated at the overall fare $s_{a b}^{1}+s_{a b}^{2}$. The last cost expression in (11) contains a term for half of AB traffic using this same demand expression. 
The first-order condition for $q_{h j}^{1}$ is computed in the same fashion as in the alliance carveout case. Imposing symmetry, the resulting equilibrium condition is the same as (10) $\left(q_{a b} / 2\right.$ replaces $d\left(s_{a b}^{1}+s_{a b}^{2}\right) / 2$ in the marginal-cost term from (11)). The first-order condition for $s_{a b}^{1}$ is

$$
\pi_{a b}^{\text {none }}=d\left(s_{a b}^{1}+s_{a b}^{2}\right)+s_{a b}^{1} d^{\prime}-C^{\prime}\left[d\left(s_{a b}^{1}+s_{a b}^{2}\right)\right] d^{\prime}-C^{\prime}\left[d\left(s_{a b}^{1}+s_{a b}^{2}\right) / 2+q_{h j}^{1}\right] d^{\prime} / 2=0 .
$$

To convert (12) into an expression involving quantities comparable to the previous conditions, the first step is to divide by $d^{\prime} / 2$. Then, recognizing that $1 / d^{\prime}\left(p_{a b}\right)=D^{\prime}\left(q_{a b}\right)$, that $d\left(p_{a b}\right)=q_{a b}$, and finally that $s_{a b}^{1}=s_{a b}^{2}=p_{a b} / 2$ holds in the symmetric equilibrium, (12) reduces to

$$
D\left(q_{a b}\right)+2 q_{a b} D^{\prime}\left(q_{a b}\right)-2 C^{\prime}\left(q_{a b}\right)-C^{\prime}\left[\left(q_{a b}+q_{h j}\right) / 2\right]=0 .
$$

Compared to the non-JV alliance condition (3), double marginalization in the AB market introduces a factor of 2 prior to the $q_{a b} D^{\prime}\left(q_{a b}\right)$ term. Given $D^{\prime}<0$, this modification reduces marginal revenue and tends to lead to a smaller value of $q_{a b}$ (and thus a higher overall fare $\left.p_{a b}\right)$ relative to the alliance case, a result familiar from Brueckner (2001).

\subsection{Unified presentation of equilibrium conditions}

Combining the previous results, a unified presentation of the equilibrium conditions is as follows:

$$
\begin{aligned}
\Omega & \equiv D\left(q_{a b}\right)+\alpha q_{a b} D^{\prime}\left(q_{a b}\right)-2 C^{\prime}\left(q_{a b}\right)-C^{\prime}\left[\lambda\left(q_{a b}+q_{h j}\right) / 2\right]=0 \\
\Phi & \equiv D\left(q_{h j}\right)+\frac{1}{\beta} q_{h j} D^{\prime}\left(q_{h j}\right)-C^{\prime}\left[\lambda\left(q_{a b}+q_{h j}\right) / 2\right]=0
\end{aligned}
$$

where the parameters $\alpha, \beta$, and $\lambda$ take the following values:

$$
\begin{aligned}
& \text { non- } J V \text { alliance }[(3),(4)]: \quad \alpha=1, \beta=1, \lambda=1 \\
& \text { JV alliance }[(6),(7)]: \quad \alpha=1, \beta=1, \lambda=2 \\
& \text { alliance with carve-out }[(9),(10)]: \quad \alpha=1, \beta=2, \lambda=1 \\
& \text { no alliance }[(13),(10)]: \quad \alpha=2, \beta=2, \lambda=1
\end{aligned}
$$




\section{Comparing the Equilibria}

To gauge the effects of the different alliance structures, the analysis in this section attempts to compare equilibrium values of $q_{a b}$ and $q_{h j}$ across the various cases shown in (16)-(19), a comparison that also reveals differences in fares and (in some instances) consumer welfare across the cases. Given that the cases are distinguished by different values of the parameters $\alpha, \beta$, and $\lambda$, this comparison can be carried out via comparative-static analysis showing the impacts of changes in these parameters. Comparisons across the cases of airline profits and social welfare are also presented, where possible. Since some key comparisons are ambiguous, section 5 imposes more structure on the analysis by adopting linear forms for demand and marginal cost, yielding complete results based on numerical analysis.

The comparative-static results are generated by totally differentiating the equation system in (14)-(15). Let the derivatives of the $\Omega$ and $\Phi$ expressions in these equations be given by $\Omega^{a b} \equiv \partial \Omega / \partial q_{a b}, \Phi^{h j} \equiv \partial \Phi / \partial q_{h j}$, and $\Omega^{h j} \equiv \partial \Omega / \partial q_{h j}=\partial \Phi / \partial q_{a b} \equiv \Phi^{a b}=-C^{\prime \prime}\left[\lambda\left(q_{a b}+\right.\right.$ $\left.\left.q_{h j}\right) / 2\right] \lambda / 2 \geq 0$. Then, for each of the parameter combinations in (16)-(19), the following conditions are assumed to hold:

$$
\Omega^{a b}, \Phi^{h j}<0 ; \quad \Lambda \equiv \Omega^{a b} \Phi^{h j}-\Omega^{h j} \Phi^{a b}>0 .
$$

For the JV and non-JV alliance cases, (14) and (15) are just the first-order conditions for the respective maximization problems. Thus, the inequalities in (20) give the second-order conditions for these problems, which are assumed to hold. For the carve-out and no-alliance cases, however, (14)-(15) are not the same as the first-order conditions, partly because symmetry is imposed to get the former conditions. As a result, the inequalities in (20) do not exactly match the second-order conditions for the carve-out and no-alliance cases. Nevertheless, the inequalities in (20) are assumed to hold for these cases along with the relevant second-order conditions. ${ }^{5}$

The strategy is first to mechanically compute the various comparative-static derivatives. Once all the results have been derived, implications regarding the alliance structures are then developed. Consider first the effect of a change in $\alpha$ on the equilibrium quantities. Totally 
differentiating (14)-(15) with respect to $q_{a b}, q_{h j}$ and $\alpha$, the following derivatives emerge

$$
\begin{aligned}
& \frac{\partial q_{a b}}{\partial \alpha}=\frac{-\Omega^{\alpha} \Phi^{h j}}{\Lambda}=\frac{-q_{a b} D^{\prime}\left(q_{a b}\right) \Phi^{h j}}{\Lambda}<0 \\
& \frac{\partial q_{h j}}{\partial \alpha}=\frac{\Omega^{\alpha} \Phi^{a b}}{\Lambda}=\frac{q_{a b} D^{\prime}\left(q_{a b}\right) \Phi^{a b}}{\Lambda} \leq 0,
\end{aligned}
$$

where $\Omega^{\alpha}=q_{a b} D^{\prime}\left(q_{a b}\right)>0$ represents $\partial \Omega / \partial \alpha$. To understand the sign of $(22)$, recall $\Phi^{a b} \geq 0$, with equality holding when $C^{\prime \prime}=0$.

Similarly, totally differentiating (14)-(15) to derive the impacts of a change in $\beta$ yields

$$
\begin{aligned}
& \frac{\partial q_{a b}}{\partial \beta}=\frac{\Phi^{\beta} \Omega^{h j}}{\Lambda}=\frac{-\left(q_{h j} D^{\prime}\left(q_{h j}\right) / \beta^{2}\right) \Omega^{h j}}{\Lambda} \geq 0 \\
& \frac{\partial q_{h j}}{\partial \beta}=\frac{-\Phi^{\beta} \Omega^{a b}}{\Lambda}=\frac{\left(q_{h j} D^{\prime}\left(q_{h j}\right) / \beta^{2}\right) \Omega^{a b}}{\Lambda}>0
\end{aligned}
$$

where $\Phi^{\beta}=-q_{h j} D^{\prime}\left(q_{h j}\right) / \beta^{2}>0$ represents $\partial \Phi / \partial \beta$. In (23), recall $\Omega^{h j} \geq 0$, with equality holding when $C^{\prime \prime}=0$.

Finally, the impacts of a change in $\lambda$ are given by

$$
\begin{aligned}
& \frac{\partial q_{a b}}{\partial \lambda}=\frac{-\Omega^{\lambda}\left(\Phi^{h j}-\Omega^{h j}\right)}{\Lambda}=\frac{\left[\left(q_{a b}+q_{h j}\right) C^{\prime \prime} / 2\right]\left(\Phi^{h j}-\Omega^{h j}\right)}{\Lambda} \geq 0 \\
& \frac{\partial q_{h j}}{\partial \lambda}=\frac{-\Phi^{\lambda}\left(\Omega^{a b}-\Phi^{a b}\right)}{\Lambda}=\frac{\left[\left(q_{a b}+q_{h j}\right) C^{\prime \prime} / 2\right]\left(\Omega^{a b}-\Phi^{a b}\right)}{\Lambda} \geq 0,
\end{aligned}
$$

where $-\left(q_{a b}+q_{h j}\right) C^{\prime \prime} / 2=\Omega^{\lambda}=\Phi^{\lambda} \geq 0$.

The results in (21)-(26) can now be used to make comparisons between the cases. The first result is as follows:

\section{Proposition 1.}

( $i)$ Suppose that economies of density are present $\left(C^{\prime \prime}<0\right)$, and that an alliance carveout is not imposed. Then, under both the non-JV and JV alliance cases, the traffic levels $q_{a b}$ and $q_{h j}$ bear an ambiguous relationship to traffic levels in the no-alliance case. 
(ii) Suppose that economies of density are absent $\left(C^{\prime \prime} \equiv 0\right)$, and that an alliance carveout is not imposed. Then, the non-JV and JV alliance cases are indistinguishable, and the common traffic level $q_{a b}$ in these cases is higher than in the no-alliance case, while the traffic level $q_{h j}$ is lower than in the no-alliance case.

Proof: To establish part $(i)$, note first from (16)-(19) that moving from the no-alliance case to the non-JV alliance case involves decreases in both $\alpha$ and $\beta$. Next observe from (21)-(24) that, when $C^{\prime \prime}>0$, both $q_{a b}$ and $q_{h j}$ fall when $\alpha$ declines, while both traffic levels rise when $\beta$ declines. Therefore, the net change in each traffic level is ambiguous. While $\lambda$ also changes in moving to the JV alliance case, the previous ambiguity persists because of the ambiguous net impact of $\alpha$ and $\beta$. To establish part $(i i)$, note that, when economies of density are absent (when $C^{\prime \prime}=0$ ), the $C^{\prime}$ terms in (14) and (15) are constants, so that the magnitude of $\lambda$ is immaterial (the density benefits from the JV alliance then disappear). Next, observe from (21) and (23) that $\partial q_{a b} / \partial \alpha<0$ and $\partial q_{a b} / \partial \beta=0$ hold when $C^{\prime \prime}=0$. Therefore, a joint decrease in $\alpha$ and $\beta$ raises $q_{a b}$. Similarly, since $\partial q_{h j} / \partial \alpha=0$ and $\partial q_{h j} / \partial \beta>0$ hold from (22) and (24) when $C^{\prime \prime}=0$, a joint decrease in $\alpha$ and $\beta$ reduces $q_{h j}$.

Proposition 1 thus shows that, while alliances have ambiguous traffic impacts in general, cooperation in the $\mathrm{AB}$ market, and the resulting elimination of double marginalization, unambiguously raises traffic and decreases the AB fare when economies of density are absent. However, anti-competitive cooperation in the HJ market unambiguously reduces traffic in this case, raising the HJ fare. By continuity, both of these conclusions still hold when economies of density are present but sufficiently weak. Brueckner (2001) offers results analogous to Proposition 1 for a more complex model.

Part (ii) of Proposition 1 is illustrated in Figure 2. $C^{\prime}$ is equal to a constant $\mu$, so that marginal cost in the HJ market is $\mu$ while marginal cost in the $\mathrm{AB}$ market is $3 \mu$, as indicated by the horizontal lines in the figure. Marginal revenue in each market in the alliance case is given by the middle downward-sloping curve, while $M R \mathrm{~s}$ in the no-alliance case are given by the lower curve for the AB market and the upper curve for the HJ market. As can be seen, movement to the alliance case raises $q_{a b}$ and lowers $q_{h j}$. Also, note that because of the higher marginal cost of carrying an AB passenger, traffic $q_{a b}$ is lower than in the HJ market in each 
case.

The next set of results compares the alliance carve-out case to the no-alliance case, as follows:

Proposition 2. When an alliance carve-out is imposed and economies of density are present, both $q_{a b}$ and $q_{h j}$ are higher than in the no-alliance case. When economies of density are absent, $q_{a b}$ is again higher under an alliance carve-out, while $q_{h j}$ is the same as in the no-alliance case. In both situations, consumer welfare under the alliance carve-out is higher than in the no-alliance case.

Proof: From (18) and (19), moving from the no-alliance case to the alliance carve-out case involves only a decline in $\alpha$. From (21)-(22), this decline raises both $q_{a b}$ and $q_{h j}$ when $C^{\prime \prime}<0$ while leaving $q_{h j}$ unchanged when $C^{\prime \prime}=0$. With traffic at least as high in both the $\mathrm{AB}$ and HJ markets, consumer welfare is higher than in the no-alliance case.

With a carve-out, movement to an alliance eliminates double marginalization in the AB market without generating anticompetitive cooperation in the HJ market. The AB traffic boost resulting from this elimination raises traffic on the interhub HJ route as well as on the interior routes. With economies of density, this traffic gain on the HJ route lowers the marginal cost of serving passengers in the HJ market, reducing the HJ fare and increasing $q_{h j}$. Thus, cooperation in the AB market generates a positive spillover into the HJ market, and this spillover is not offset by anti-competitive behavior in that market given the carve-out. Therefore, beneficial effects in the AB market permeate the entire network. When economies of density are absent, however, the AB traffic boost has no effect on marginal cost on the HJ route, eliminating the positive spillover.

As before, the conclusions of Proposition 2 can be illustrated in Figure 2 in the absence of economies of density. With the carve-out, the upper curve continues to represent marginal revenue in the HJ market even after formation of the alliance, while marginal revenue in the AB market again shifts from the lower curve to the middle curve. Thus, $q_{a b}$ rises under the carve-out while $q_{h j}$ is unchanged relative to the no-alliance case.

The final set of results focuses on the JV alliance: 


\section{Proposition 3.}

(i) With economies of density, a JV alliance leads to higher traffic levels $q_{a b}$ and $q_{h j}$ in both markets than a non-JV alliance and thus a higher level of consumer welfare.

(ii) Imposing a carve-out on a non-JV alliance raises traffic levels in at least one market, thus increasing consumer welfare. But, when economies of density are present, imposing a carve-out on a JV alliance yields ambiguous effects on traffic and consumer welfare.

Proof: Part $(i)$ is established by noting from (16)-(17) that a movement from a non-JV alliance to a JV alliance involves an increase in $\lambda$. From (25)-(26), this increase raises both $q_{a b}$ and $q_{h j}$ when $C^{\prime \prime}>0$, increasing consumer welfare. Part $(i i)$ is established by observing that imposing a carve-out on a non-JV alliance involves an increase in $\beta$. From (23)-(24), this increase raises both traffic levels when $C^{\prime \prime}>0$, while leaving $q_{a b}$ unchanged when $C^{\prime \prime}=0$. In either case, consumer welfare rises. But when a carve-out is imposed on a JV alliance, $\lambda$ falls while $\beta$ rises. Given (23)-(26), these changes move $q_{a b}$ and $q_{h j}$ in opposite directions when economies of density are present. Net changes in traffic, and thus the impact on consumer welfare, are then ambiguous.

Since the JV alliance allows better exploitation of economies of density than a non-JV alliance with no change in airline behavior, the benefits cited in part $(i)$ of the Proposition are straightforward. In addition, since imposing a carve-out on a non-JV alliance eliminates anticompetitive cooperation in the HJ market while involving no sacrifice of economies of density, the benefits of doing so are clear. By contrast, imposing a carve-out on a JV alliance generates opposing effects. Preventing collaboration in the HJ market generates a competitive benefit while preventing the JV's more-effective exploitation of economies of density. As a result, the net effects on traffic levels and consumer welfare are ambiguous. This finding recalls the standard conclusion regarding a merger of two firms producing with increasing returns. Whether such a merger is beneficial depends on size of the competitive loss relative to the gains from better exploitation of scale economies.

Since economies of density are present, making marginal cost non-constant, Figure 2 cannot be used to illustrate Proposition 3 in a rigorous fashion. However, a few suggestive observations can be made. First, with a JV alliance leading to lower costs, both the horizontal cost lines 
in the figure will shift down relative to the non-JV case, raising alliance traffic levels and illustrating the first part of the proposition. Note, however, that the extent of this downward cost shift is endogenous since it depends on the traffic levels themselves. To illustrate the second part of the proposition, Figure 2 can be viewed as illustrating the initial JV case. Then, a carve-out will tend to raise the height of the cost lines, while at the same time raising marginal revenue in the HJ market from the middle to the upper curve. From the figure, it can be seen that these combined shifts produce an ambiguous effect on $q_{h j}$. However, since the cost-line heights are themselves endogenous, the figure cannot rigorously illustrate the outcome.

The results in Propositions 1-3 lead to a partial ranking of the four cases under consideration from the consumer's point of view. The three alliance cases can be ranked in either of two orders: alliance carve-out/JV alliance/non-JV alliance or JV alliance/alliance carve-out/nonJV alliance. The no-alliance case is ranked below a carve-out, but otherwise it can appear anywhere in these lists.

The cases can also be ranked from the perspective of airline profits. Since both the JV and non-JV alliances involve full coordination between the carriers, while costs are lower under the JV alliance due to consolidated operations, aggregate profit is higher in the JV case. Moreover, since movement from the no-alliance case to a non-JV alliance involves coordination in both markets and no change in costs, the non-JV alliance is more profitable (implying that a JV alliance is also superior to no alliance). In addition, since movement from the alliance carveout case to a non-JV alliance involves the introduction of coordination in the one market where it is missing, profit grows (implying that a JV alliance is also more profitable than a carve-out). However, the profit differerence between the no-alliance and carve-out cases is ambiguous. Coordination in the AB market under the carve-out tends to raise profit, but since cooperation is absent in the HJ market, this tendency does not necessarily raise the combined profit of the carriers. Thus, the profit ranking of the cases is JV alliance/non-JV alliance/no alliance, with a carve ranked either third or fourth.

With both profit and consumer welfare higher under a JV alliance than a non-JV alliance, social welfare is higher in the JV case. However, welfare comparisons among the other cases are ambiguous in general. To carry out such comparisons, and to dispel other ambiguities of 
the general model, the next section imposes linear functional forms for demand and marginal cost while assuming that consumer surplus is a valid measure of consumer welfare (requiring the absence of income effects on demand). ${ }^{6}$

\section{Numerical Example}

\subsection{The setup}

The analysis of section 4 leaves some key ambiguities: whether imposing a carve-out on a JV alliance is beneficial for consumers; whether either type of alliance is better for consumers than the no-alliance case; how the cases rank in terms of social welfare. These ambiguities can only be resolved by imposing more structure on the model, and the purpose of the present section is to do so by assuming linear forms for the demand and marginal-cost functions, following similar numerical analysis in Brueckner (2001). Thus, the demand function is given by $D(q)=\gamma-q / 2$ and the marginal-cost function by $C^{\prime}(T)=1-\theta T$. Observe that this marginal-cost function is downward sloping, indicating economies of density. Note also that, for simplicity, the demand slope and marginal-cost intercept are both normalized, leaving a two-dimensional $(\gamma, \theta)$ parameter space. ${ }^{7}$

The first step is to derive the feasible region in this parameter space, where several restrictions are satisfied. Under each of the cases, three requirements must be met: the conditions in (20) must hold; the traffic levels $q_{a b}$ and $q_{h j}$ must be positive; marginal costs on the two route segments operated by each carrier must be positive (given the form of $C^{\prime}(T)$, negative values are possible for large traffic levels). While these requirements generate a feasible $(\gamma, \theta)$ region for each of the four cases (JV alliance, non-JV alliance, etc.), the intersection of these four regions is the relevant feasible region for the analysis. In this region, the three requirements are met for all the cases.

The conditions in (20) for each case imply an upper bound on $\theta$, and the most stringent of these restrictions is $\theta \leq 0.19$. To understand the restrictions implied by the nonnegativity requirements, consider a simple setting where an increasing-returns-to-scale monopolist serves a single market, and suppose that the linear demand and marginal-cost curves from above are relevant. The equilibrium is given by the intersection of downward-sloping $M C$ and $M R$ 
curves, with the latter being steeper. In order for this intersection to occur above the quantity axis, yielding positive $M C$ and $M R$ values, the $M C$ slope parameter $\theta$ cannot be too large relative to the $M R$ intercept parameter $\gamma$. Conversely, to generate a positive quantity, $\gamma$ cannot be smaller than the $M C$ intercept. While the present context is more complex, similar restrictions emerge, yielding the feasible region shown in Figure 3. The region's curved right border corresponds to the positive-MC restriction, which is tightest for the JV alliance case, and the nearly vertical left border corresponds to the positive-quantity restriction, which is tightest for the non-JV alliance case. ${ }^{8}$

The numerical analysis carries out pairwise comparisons between each of the four cases (e.g., JV vs. non-JV alliance), comparing traffic levels, consumer surplus, profit, and social welfare (consumer surplus plus profit) between the cases throughout the feasible region. When the comparisons yield complex patterns, the results are illustrated graphically.

\subsection{Basic findings}

JV vs. non-JV alliance: Proposition 3(i) indicates that traffic levels in both markets are higher under the JV alliance than under the non-JV alliance, and this finding is confirmed numerically. In addition, the computations show that consumer surplus, profit and social welfare are all higher under a JV alliance throughout the feasible region, as expected.

Carve-out vs. non-JV alliance: Proposition 3(ii) indicates that traffic levels are higher in both markets under a carve-out than under a non-JV alliance, and this finding is confirmed numerically. Consumer surplus is then higher and profit lower under the carve-out, as expected. The results show that the former effect dominates, so that social welfare is higher throughout the feasible region under a carve-out than under a non-JV alliance.

Carve-out vs. no alliance: Proposition 2 indicates that traffic levels in both markets are higher under a carve-out than with no alliance, and this finding is confirmed numerically. Consumer surplus is thus higher under the carve-out as expected, but profit is lower over a narrow vertical strip at the upper left edge of the feasible region, though larger otherwise. The surplus effect dominates, so that welfare is higher under a carve-out than with no alliance throughout the feasible region.

While the above findings are mostly predicted by the propositions, the following compar- 
isons resolve some key questions left ambiguous by the theory.

Non-JV alliance vs. no alliance: While Proposition 1 indicates that this comparison is ambiguous in general, the numerical results show that $q_{a b}$ is higher under a non-JV alliance than with no alliance, and that $q_{h j}$ is lower, relationships that hold throughout the feasible region. Note that these relationships match those emerging in the absence of economies of density (see Proposition 1). Since the consumer surplus gain in the AB market is smaller than the loss in the HJ market, overall surplus is lower under the alliance throughout the feasible region, while profit is higher (as expected). Because of these opposing changes, the welfare comparison depends on parameter values, as seen in Figure 4. Welfare under the alliance is higher in the white part of the feasible region but lower in the grey portion, where the demand intercept $\gamma$ takes small values. Thus, relative to no alliance, a non-JV alliance is welfare enhancing unless travel demand is low.

JV alliance vs. no alliance: This comparison is again ambiguous in general, but the numerical results again show that $q_{a b}$ is higher (and $q_{h j}$ lower) under the alliance throughout the feasible region. Although consumer surplus is lower under the JV alliance over nearly all the feasible region, this relationship is reversed in the sliver of white area shown in Figure 5, where $\theta$ is large and demand is as large as possible for the given $\theta$ range. Thus, an increase in consumer surplus is possible under the JV alliance when economies of density are strong, reinforcing the increase in profit. This more favorable picture, which is a result of the gains from consolidated JV operations, leads to a better welfare comparison than under the non-JV alliance. Relative to the no-alliance case, the JV alliance leads to higher welfare over a greater portion of the feasible region, as seen in Figure 6 (the white area is larger than in Figure 4).

Carve-out vs. JV alliance: The general ambiguity in this comparison is also resolved by the numerical results. In contrast to the non-JV vs. carve-out comparison, $q_{a b}$ is lower under the carve-out than under the JV alliance throughout the feasible region, while $q_{h j}$ is again higher under the carve-out. A lower $q_{a b}$ emerges because the loss of benefits from consolidated operations caused by the carve-out raises marginal cost on the HJ route even though the increase in $q_{h j}$ tends to reduce $M C$ via economies of density. This increase in $M C$ depresses $\mathrm{AB}$ traffic even though cooperation in market $\mathrm{AB}$ is unchanged in moving from the alliance 
to the carve-out. Note that the increase $q_{h j}$ occurs despite the higher marginal cost on the HJ route, being a consequence of the elimination of anticompetitive HJ cooperation under the carve-out.

Appraising the net effect of these traffic changes, the carve-out raises consumer surplus throughout the feasible region while reducing profit. The welfare comparison is shown in Figure 7, with welfare under carve-out higher than under the JV alliance in the grey area and lower in the white area. Thus, imposing a carve-out on a JV alliance is usually desirable but is welfare reducing when $\theta$ is large and demand is at the high end of the feasible region over this $\theta$ range. This conclusion makes intuitive sense given that imposition of a carve-out requires sacrificing the benefits from consolidated operations, which are greatest when $\theta$ is large and economies of density are strong.

Another observation, which comes from comparing Figures 6 and 7, is that the region where a JV alliance is superior to a carve-out in Figure 7 is contained within the region in Figure 6 where the JV alliance is superior to no alliance. Therefore, a JV-alliance is better than a carve-out only when the alliance is itself preferred to no alliance.

The main lessons of the numerical analysis are summarized as follows:

\section{Proposition 4.}

(i) $J V$ and non-JV alliances lead to higher social welfare than the no-alliance case unless travel demand is low, in a sense made precise in Figures 4 and 6.

(ii) An alliance carve-out leads to higher social welfare than both the no-alliance and $J V$-alliance cases.

(iii) Imposing a carve-out on a JV alliance reduces social welfare when economies of density are strong, in a sense made precise in Figure 7, raising welfare otherwise.

Note that part $(i i)$ of the proposition mirrors the general conclusions regarding a carve-out's impact on consumer, as opposed to social, welfare (Propositions 2, 3(ii)).

\subsection{The effect of a larger $A B$ market}

Given that alliances are designed to benefit interline passengers, it is useful to explore the effect of increasing the size of $\mathrm{AB}$ market, where interline travel is required, relative to the HJ 
market's size. This change is realistic since, for most alliances, hub-to-hub markets are small relative to the collection of interline markets they serve. Accordingly, the numerical analysis is redone under the assumption that the demand intercept in the $\mathrm{AB}$ market is $3 \gamma$, with the HJ intercept remaining at $\gamma$. This change leads to a smaller feasible region, whose upper boundary at any given $\gamma$ is closer to the horizontal axis. ${ }^{9}$

With a larger $\mathrm{AB}$ market, the JV alliance is preferred to no alliance over a larger share of the feasible region, as seen in Figure 8. As before, the JV alliance leads to lower welfare when demand is low, but this (grey) region is relatively small, as seen in the figure. This typically positive welfare outcome partly reflects the JV alliance's better performance in generating consumer surplus. As seen in Figure 9, the white area where surplus is higher under the alliance grows from the small sliver in Figure 5 to an area that comprises most of the feasible region. This change makes sense given that the interline passengers, who benefit from the alliance, are now relatively larger in number. Similar conclusions apply to the comparison between a non-JV alliance and no alliance, which yields diagrams similar to Figures 8 and 9.

Another interesting impact of the larger AB market is seen in Figure 10, which compares the level of $q_{h j}$ between the JV and no-alliance cases. Within the small white area in the figure, traffic in market HJ is higher under the alliance despite the restraining effect of cooperative pricing in that market. This outcome derives partly from the gain due to consolidated operations under the alliance, but it also reflects the greater weight of the increase in AB traffic, which serves to further push down marginal cost on the HJ route and to offset the effect of anticompetitive pricing. ${ }^{10}$

Finally, Figure 11 compares welfare in the JV alliance and carve-out cases. The white area, where imposing a carve-out on a JV alliance reduces welfare, now comprises a larger portion of the feasible region. ${ }^{11}$ Thus, a carve-out is more likely to be undesirable when the interline markets are large relative to the hub-to-hub market.

\subsection{Recommendations for regulators}

When presented with an alliance's application for antitrust immunity, regulators must decide whether to approve the application outright, deny it, or to require modifications. Based on the preceding numerical analysis, the proper course can be identified. If the ATI application 
involves a non-JV alliance, then regulators should approve the application subject to a carveout. This conclusion follows from Proposition 4(ii), which indicates higher welfare under a carve-out than under both the non-JV alliance (the outcome under full approval of the ATI application) and the no-alliance case (the outcome under denial of the application).

Whether the airlines accept the regulator's offer of a carve-out depends on profits relative to the no-alliance case, their fall-back position. While carve-out profit is always higher when the $\mathrm{AB}$ market is large, carve-out profit is lower than in the no-alliance case over a small part of the feasible region when the $\mathrm{AB}$ and $\mathrm{HJ}$ markets have the same size, as mentioned above. If the $(\gamma, \theta)$ parameters lie in this small region, then the airlines will reject the carve-out offer, choosing not to pursue their alliance, but they will accept it otherwise.

If the ATI application involves a JV alliance, then by Proposition 4(iii), the regulators should grant full approval if the parameters lie in the white region in Figure 7 or Figure 11. Since this region is larger in Figure 11, the regulators should more readily grant full ATI approval when the interline markets served by the alliance are large in total relative to the hub-to-hub market (or conversely, when the hub-to-hub market is small). Otherwise, the application should be approved subject to a carve-out. As in the non-JV case, denial of the ATI application is never warranted given that a carve-out yields higher welfare than no alliance. As before, the airlines may again choose not to accept a carve-out offer for some parameter values. ${ }^{12}$

\section{Conclusion}

This paper has offered the first formal economic analysis of carve-outs under airline antitrust immunity. Carve-outs are designed to limit the potential anticompetitive effects of cooperation by alliance partners in hub-to-hub markets, where they provide overlapping nonstop service. While the paper shows that carve-outs are beneficial when the alliance does not involve full integration of the partners' operations on the hub-to-hub route, its key point is that a carve-out may be harmful when imposed on a joint-venture alliance. A JV alliance involves full exploitation of economies of traffic density on the hub-to-hub route (as well as other synergies not captured by the model), and a carve-out prevents the realization of these bene- 
fits. While a carve-out may limit anticompetitive incentives on the hub-to-hub route, welfare may be reduced if the resulting gains are overshadowed by the efficiency loss generated by the carve-out, an outcome that arises in the model when economies of traffic density are strong. This argument, which has been made by the airlines themselves, finds its first formalization in the paper, and regulators may wish to give it some credence. 


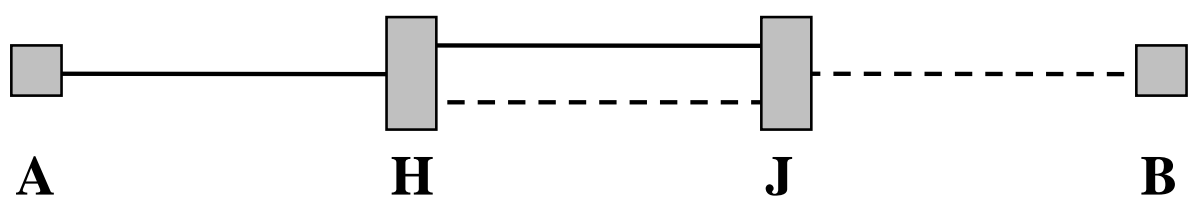

Figure 1: Network structure 


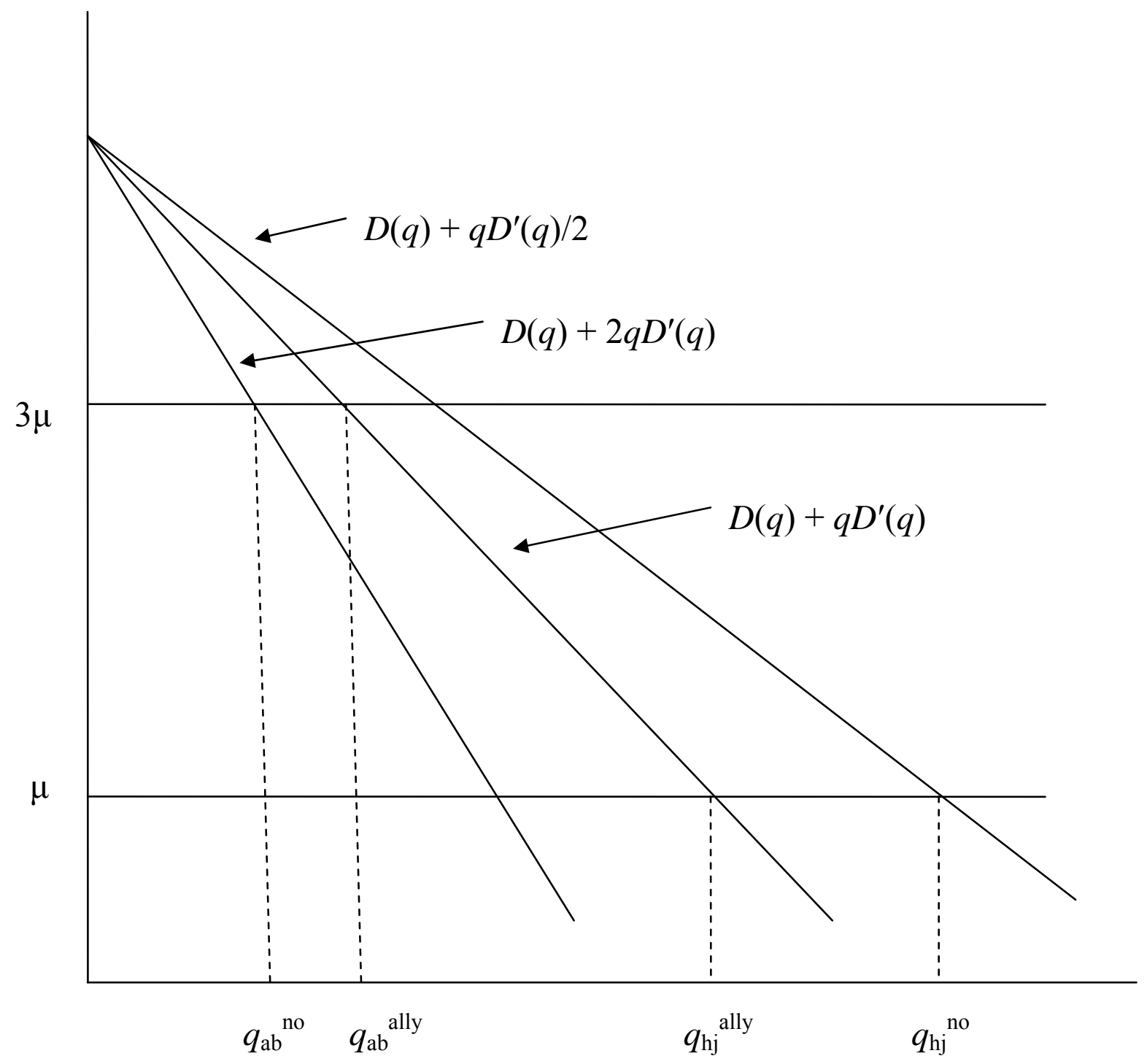

Figure 2: Alliance vs. no alliance without economies of density 


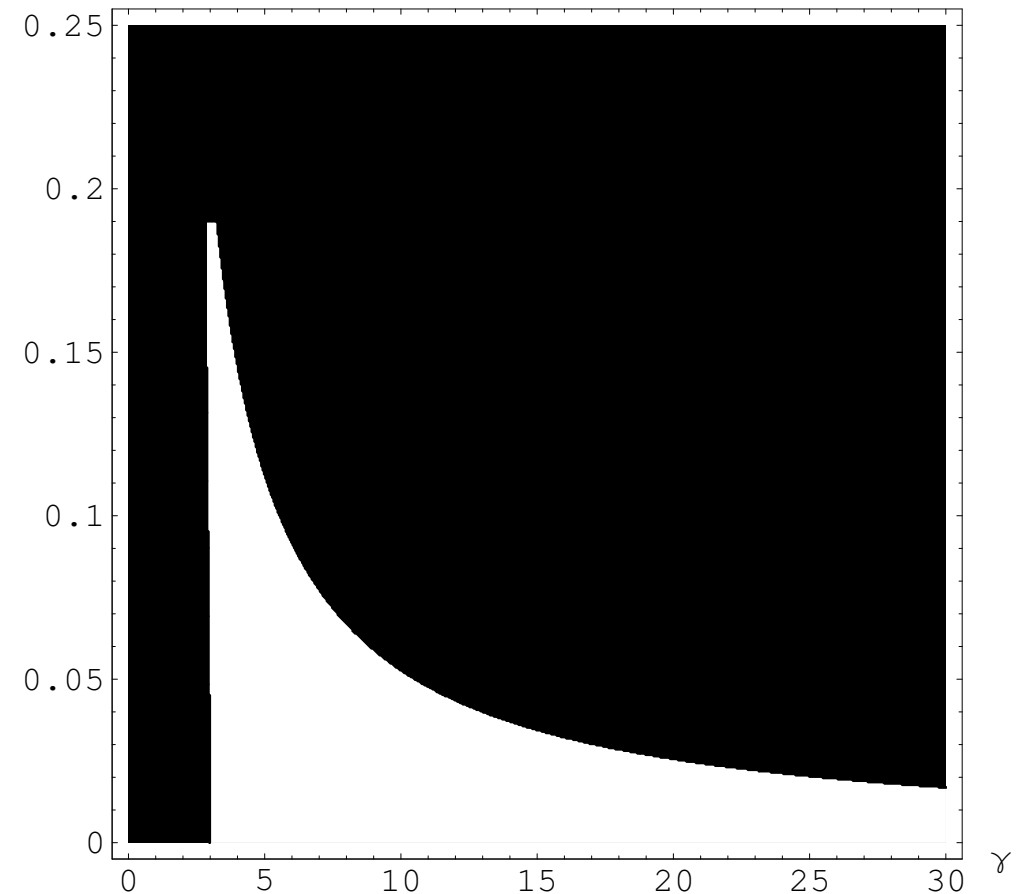

Figure 3: Feasible region

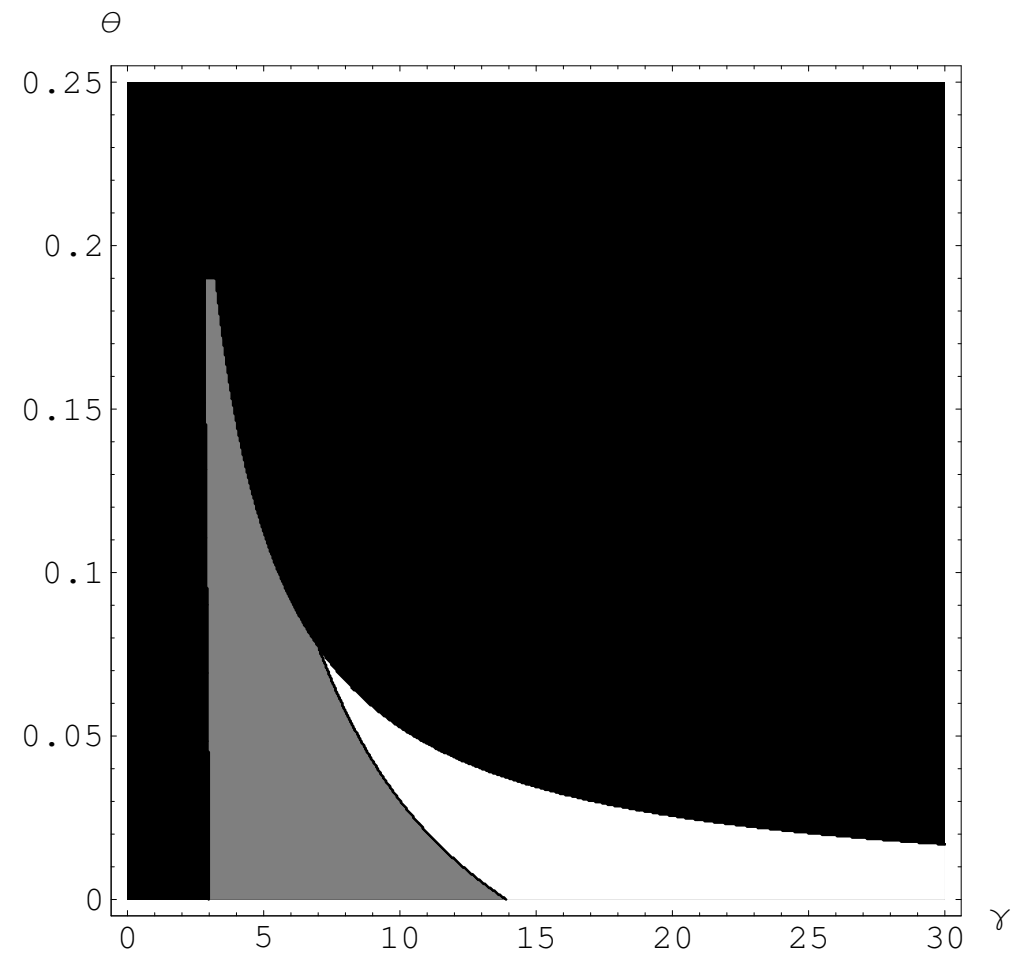

Figure 4: Welfare difference, non-JV alliance vs. no alliance (white +, grey -) 


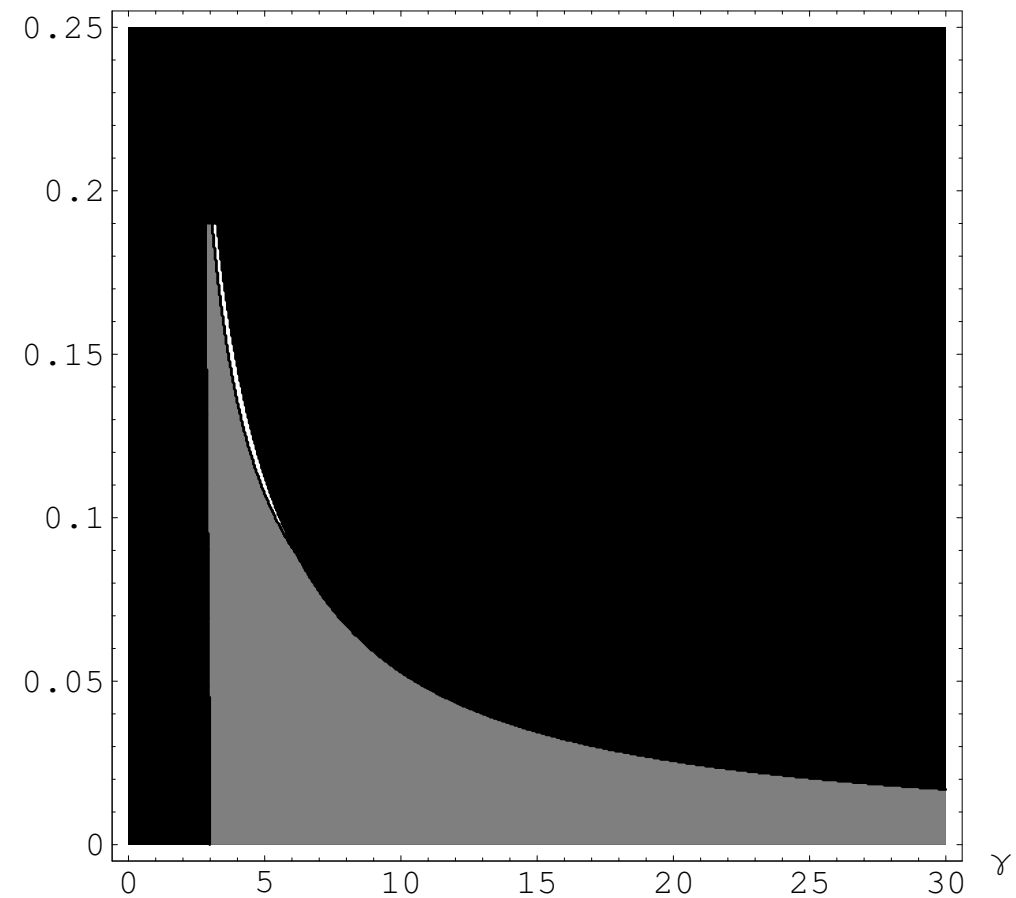

Figure 5: Consumer-surplus difference, JV alliance vs. no alliance (white + , grey -$)$

$\theta$

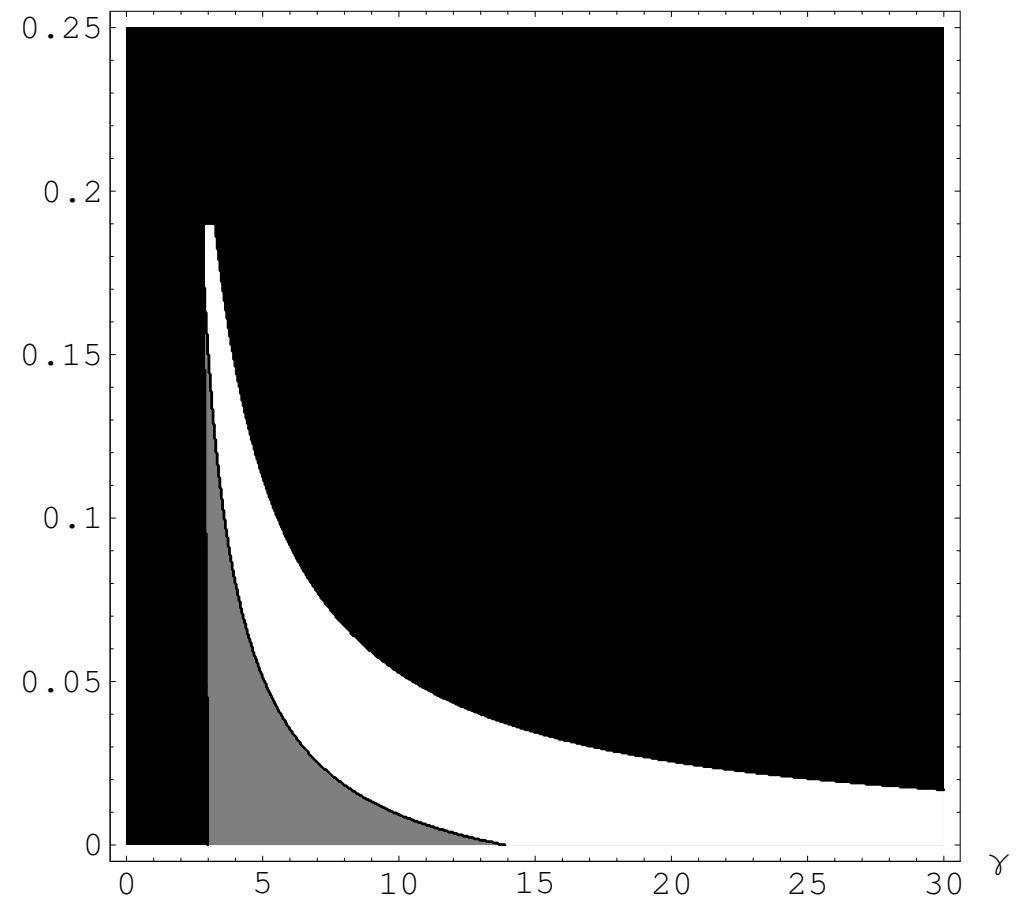

Figure 6: Welfare difference, JV alliance vs. no alliance $($ white + , grey -$)$ 


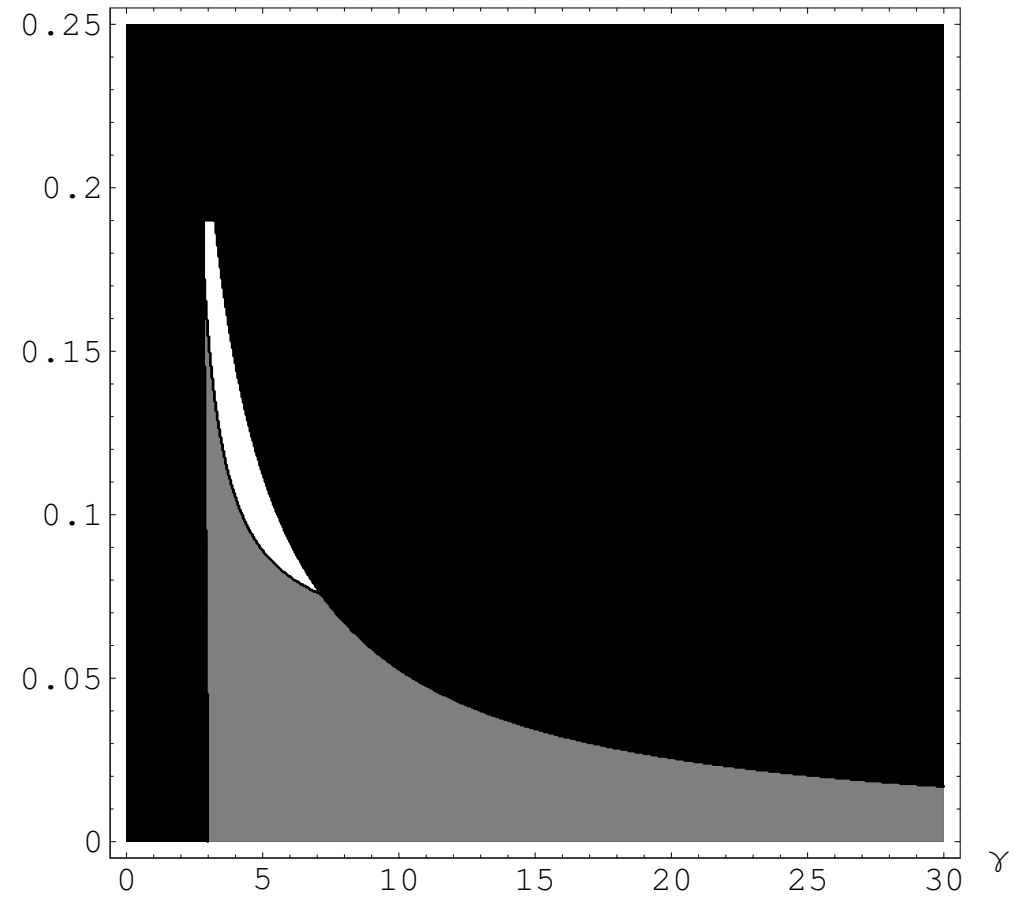

Figure 7: Welfare difference, JV alliance vs. carve-out (white + , grey -)

$\theta$

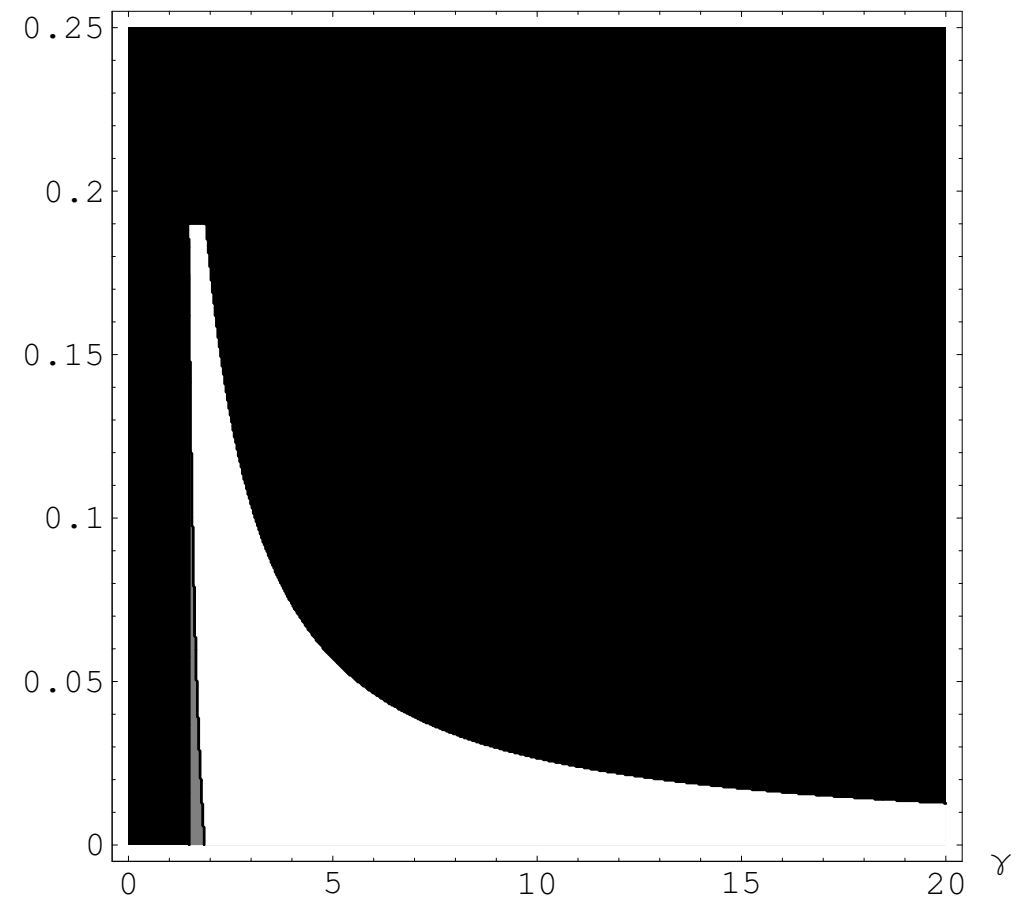

Figure 8: Welfare difference, JV alliance vs. no alliance with large AB market (white +, grey -) 


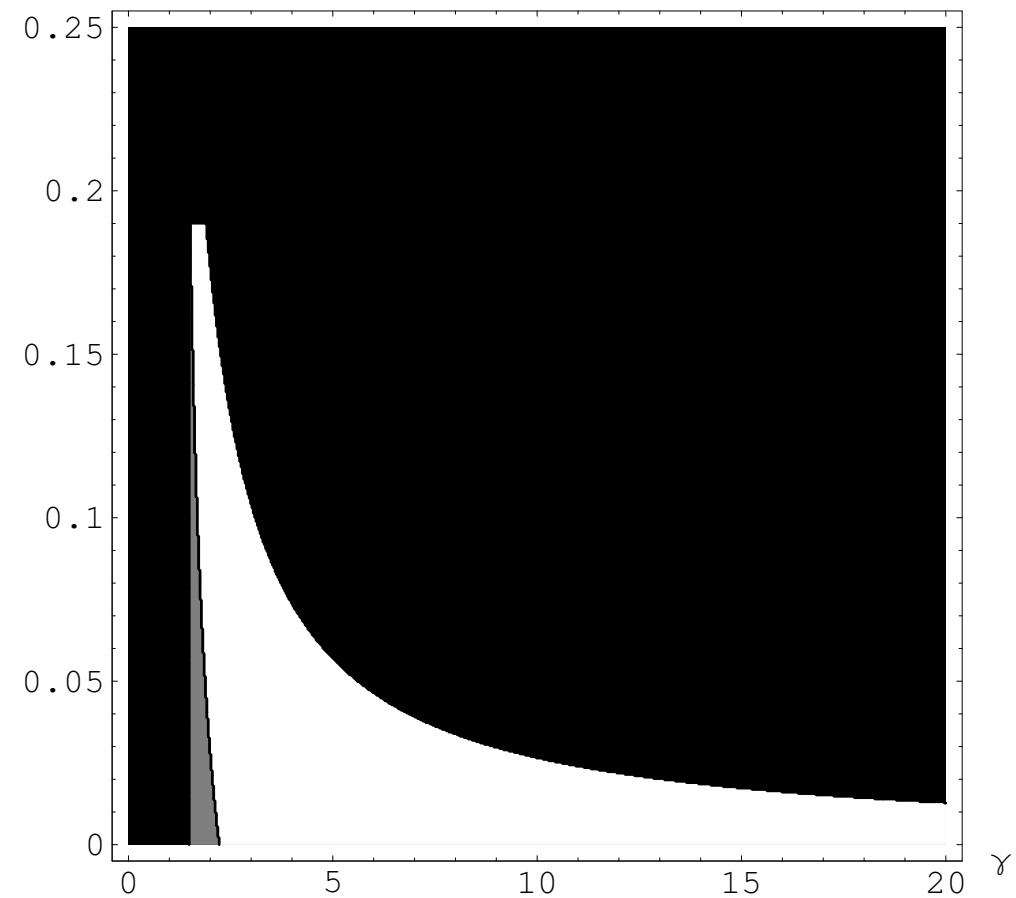

Figure 9: Consumer-surplus difference, JV alliance vs. no alliance with large $\mathrm{AB}$ market

(white +, grey -)

$\theta$

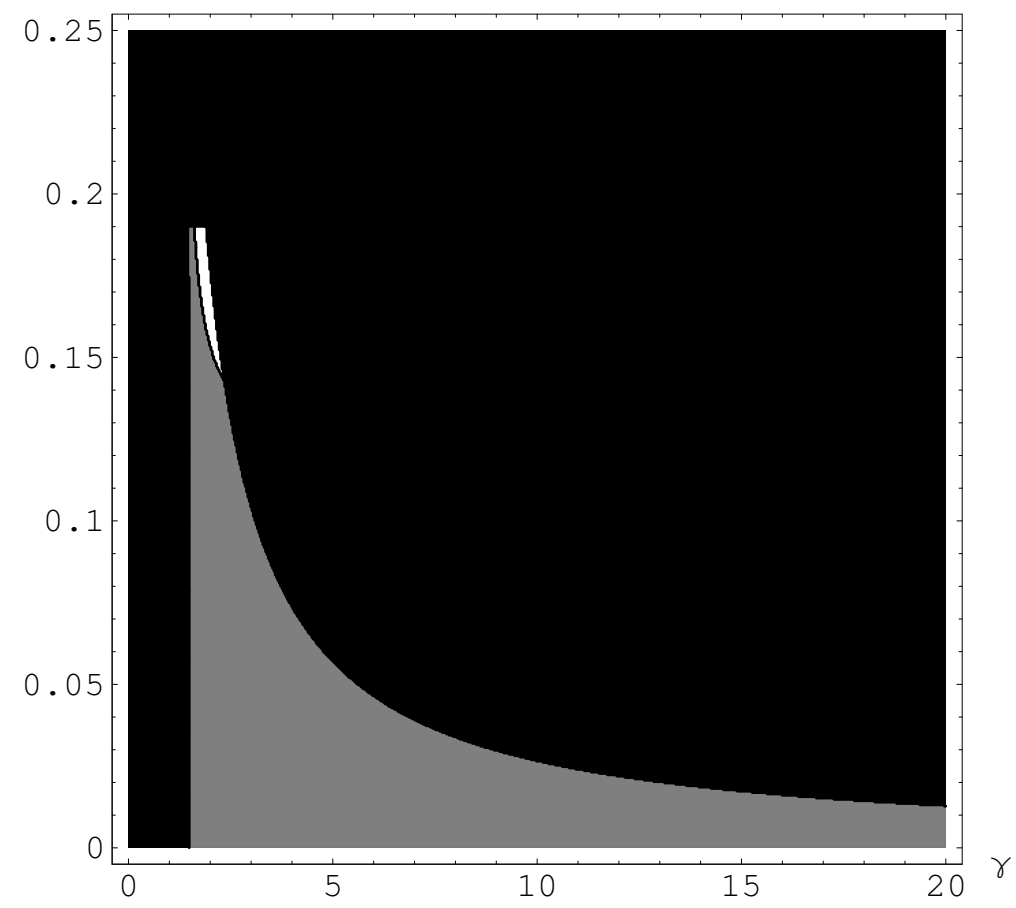

Figure 10: HJ traffic difference, JV alliance vs. no alliance with large AB market

(white + , grey -) 


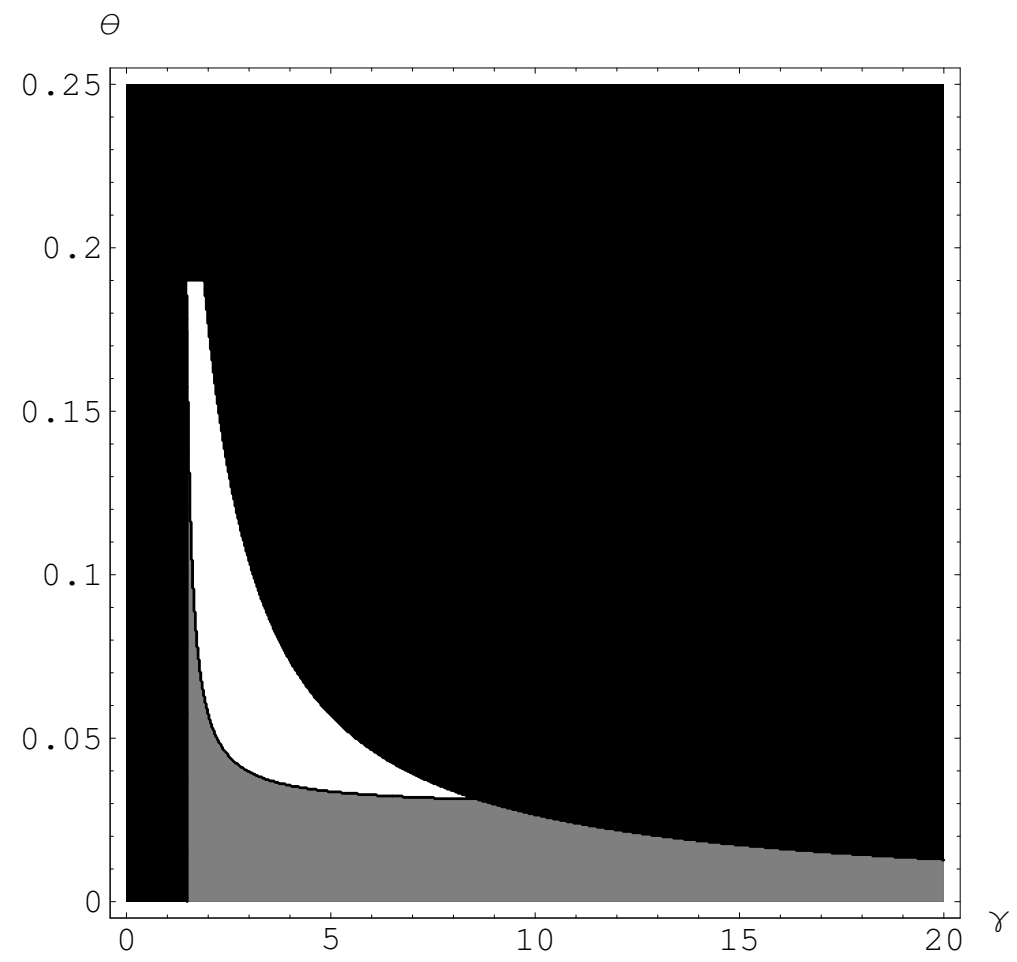

Figure 11: Welfare difference, JV alliance vs. carve-out with large AB market $($ white + , grey -$)$ 


\section{References}

American Airlines, 2009. Reponse of American Airlines to the comments of the Department of Justice. In DOT Docket OST-2008-0234 (http://www.regulations.gov/fdmspublic/ component $/$ main? main=DocketDetail\&d=DOT-OST-2008-0234).

Bamberger, G., Carlton, D., Neumann, L., 2004. An empirical investigation of the competitive effects of domestic airline alliances. Journal of Law and Economics 47, 195222.

Barla, P., Constantatos, C., 2006. On the choice between strategic alliance and merger in the airline sector: The role of strategic effects. Journal of Transport Economics and Policy 40, 409-424.

Bilotkach, V., 2005. Price competition between international airline alliances. Journal of Transport Economics and Policy 39, 167-189.

Bilotkach, V., 2007. Airline partnerships and schedule coordination. Journal of Transport Economics and Policy 41, 413-425.

Brueckner, J.K., Whalen, W.T., 2000. The price effects of international airline alliances, Journal of Law and Economics 43, 503-545.

Brueckner, J.K, 2001. The economics of international codesharing: An analysis of airline alliances. International Journal of Industrial Organization 19, 1475-1498.

Brueckner, J.K., 2003. International airfares in the age of alliances: The effects of codesharing and antitrust immunity. Review of Economics and Statistics 85, 105-118.

Chen, Y., Gayle, P., 2007. Vertical contracting between airlines: An equilibrium analysis of codeshare alliances. International Journal of Industrial Organization 25, 1046-1060.

De Borger, B., Dunkerley, F., Proost, S., 2007. Strategic investment and pricing decisions in a congested transport corridor. Journal of Urban Economics 62, 294-316.

De Borger, B., Proost, S., Van Dender, K., 2008. Private port pricing and public investment in port and hinterland capacity. Journal of Transport Economics and Policy 42, 527-561.

Flores-Fillol, R., Moner-Colonques, R., 2007. Strategic formation of airline alliances. Journal of Transport Economics and Policy 41, 427-449. 
Gayle, P., 2007. Airline code-share alliances and their competitive effects. Journal of Law and Economics 50, 781-819.

Gayle, P., 2008. An empirical analysis of the competitive effects of the Delta/Continental/ Northwest codeshare alliance. Journal of Law and Economics 51, 743-766.

Hassin, O., Shy, O., 2004. Code-sharing agreements and interconnections in markets for international flights. Review of International Economics 12, 33752.

Ito, H., LeE, D., 2007. Domestic codesharing, alliances and airfares in the U.S. airline industry, Journal of Law and Economics 50, 355-380.

Oum, T.H., Park, J.-H., Zhang, A., 1996. The effects of airline codesharing agreements on firm conduct and international air fares, Journal of Transport Economics and Policy 30, 187-202.

Oum, T.H., Yu, C., Zhang, A., 2001. Global airline alliances: International regulatory issues. Journal of Air Transport Management 7, 57-62.

PARK, J.-H., 1997. The effect of airline alliances on markets and economic welfare, Transportation Research Part E 33, 181-195.

PARK, J., PARK, N., ZhAng, A., 2003. The impact of international alliances on rival firm value: A study of the British Airways/USAir alliance. Transportation Research Part E 39, $1-18$.

PARK, J.-H., ZhANG, A., 1998. Airline alliances and partner firms' output, Transportation Research Part E 34, 245-255.

PARK, J.-H., Zhang, A., 2000. An empirical analysis of global airline alliances: Cases in the north Atlantic markets, Review of Industrial Organization 16, 367-384.

PARK, J., ZhAng, A., ZhAng, Y., 2001. Analytical models of international alliances in the airline industry. Transportation Research Part B 35, 865-886.

US Department of Justice, 2009. Public version, Comments of the Department of Justice on the show cause order. In DOT Docket OST-2008-0234 (http://www.regulations.gov/ fdmspublic/component/main?main=DocketDetail\&d=DOT-OST-2008-0234).

US Department of Transportation, 2009. Final order. In DOT Docket OST-2008-0234 (http://www.regulations.gov/fdmspublic/component/main?main=DocketDetail\&d=DOTOST-2008-0234).

Whalen, W.T., 2007. A panel data analysis of code sharing, antitrust immunity and open 
skies treaties in international aviation markets. Review of Industrial Organization 30, 39-61.

Willig, R., Israel, M., Keating, B., 2009. Competitive effects of airline antitrust immunity. Unpublished paper, Compass Lexecon. 


\section{Footnotes}

${ }^{*}$ We thank Ricardo Flores-Fillol for comments. Errors, however, are our responsibility.

${ }^{1}$ See Barla and Constantatos (2004), Bilotkach (2005, 2007), Chen and Gayle (2007), FloresFillol and Moner-Colonques (2007), Hassin and Shy (2004), Oum, Park and Zhang (1996), Oum, Yu and Zhang (2001), Park (1997), Park, Park and Zhang (2003), Park and Zhang $(1998,2000)$ and Park, Zhang and Zhang (2001). See Bamberger, Carlton and Newman (2004), Ito and Lee (2007), and Gayle $(2007,2008)$ for studies of domestic airline alliances.

${ }^{2}$ Like the rest of the alliance literature, the model treats the number of potential alliance partners as fixed, abstracting from entry and exit. Conceivably, higher profits due to alliance formation could prompt the entry of new carriers also seeking to form immunized alliances. However, exploration of this phenomenon is beyond the scope of the paper but could be a subject for future research.

${ }^{3}$ Note that the ordering of the city names in HJ is simply alphabetical, not signifying directionality. This market could equally well be denoted JH.

${ }^{4}$ For $\mathrm{AB}$ passengers originating at $\mathrm{A}$, airline 1 would receive a subfare for carrying the passenger over two route segments (AH and $\mathrm{HJ}$ ), while airline 2 would receive a smaller subfare for carrying the passenger over a single route segment (BJ). For AB passengers originating at $\mathrm{B}$, the reverse statement would apply, with airline 2 receiving a large and 1 a small subfare. The subfare $s_{a b}^{1}$ from above can be viewed as the average of airline 1's large and small subfares for these two types of trips, and similarly for $s_{a b}^{2}$ and airline 2. See the appendix to Brueckner (2001) for formal discussion of this point in a more-complex model.

${ }^{5}$ It can be shown that satisfaction of $\Omega^{a b}, \Phi^{h j}<0$ implies satisfaction of the corresponding inequalities in the carve-out second-order conditions. However, a similar connection cannot be established for the no-alliance case. As for the other inequality in (20), $\Omega^{a b} \Phi^{h j}-\Omega^{h j} \Phi^{a b}>$ 0 , this condition can be imposed if stability of the carve-out and no-alliance equilibria is required. It should be noted that, when demand and marginal cost are linear, as in the numerical analysis presented below, satisfaction of the conditions in (20) ensures satisfaction of the second-order conditions for all four cases in (16)-(19).

${ }^{6}$ The model could be modified to assume that economies of density are eventually exhausted, with MC becoming constant at a value $m$ above some threshold level of $T$. Then, three types of regimes could be distinguished: (a) all the alliance cases have $M C=m$, so that Propositions 1(ii) and 3(ii) hold; (b) all cases have $M C>m$, so that all the existing results apply; $(c)$ some cases have $M C=m$ and some have $M C>m$. Under regime $(c)$, the 
JV alliance case would be the one most likely to achieve $M C=m$, limiting its welfare advantage.

${ }^{7}$ Note that one normalization can be made by appropriate choice of units but that the second one is arbitrary.

${ }^{8}$ Since it can be shown that $q_{a b}<q_{h j}$ holds under each case, the nonnegativity restriction on $q_{a b}$ need only be considered. That restriction reduces to $\theta \geq 3-\gamma$. In addition, given that traffic on the $\mathrm{AB}$ route is then smaller than on the HJ route, the positive $M C$ condition need only be considered for the HJ route.

${ }^{9}$ Identification of this region is more complicated than before since the market with the smallest traffic level or smallest $M C$ is no longer clear a priori (see footnote 9 ).

${ }^{10} \mathrm{~A}$ similar area is not present in the corresponding figure for the comparison of the non-JV and no-alliance cases, a consequence of the absence of consolidation gains.

${ }^{11}$ The carve-out now reduces consumer surplus as well over a region similar in appearance to the white region in Figure 7.

${ }^{12}$ When the $\mathrm{AB}$ and HJ markets are of equal size, the area where carve-out profit is lower than no-alliance profit extends slightly into the area in Figure 7 where a carve-out would be offered. However, with a larger AB market, a carve-out offer is never rejected. 